\title{
Probing the nanoadhesion of Streptococcus sanguinis to titanium implant surfaces by atomic force microscopy
}

This article was published in the following Dove Press journal:

International Journal of Nanomedicine

6 April 2016

Number of times this article has been viewed

\section{Sebastian Aguayo' \\ Nikolaos Donos ${ }^{2}$ \\ Dave Spratt ${ }^{3}$ \\ Laurent Bozec}

'Department of Biomaterials and Tissue Engineering, ${ }^{2}$ Periodontology Unit, ${ }^{3}$ Division of Microbial Diseases, UCL Eastman Dental Institute, University College London, London, UK
Correspondence: Laurent Bozec Division of Biomaterials and Tissue Engineering, UCL Eastman Dental Institute, University College London, 256 Gray's Inn Road, London, WCIX 8LD, UK

Email I.bozec@ucl.ac.uk

\begin{abstract}
As titanium (Ti) continues to be utilized in great extent for the fabrication of artificial implants, it is important to understand the crucial bacterium-Ti interaction occurring during the initial phases of biofilm formation. By employing a single-cell force spectroscopy technique, the nanoadhesive interactions between the early-colonizing Streptococcus sanguinis and a clinically analogous smooth Ti substrate were explored. Mean adhesion forces between $S$. sanguinis and Ti were found to be $0.32 \pm 0.00,1.07 \pm 0.06$, and $4.85 \pm 0.56 \mathrm{nN}$ for 0,1 , and 60 seconds contact times, respectively; while adhesion work values were reported at 19.28 $\pm 2.38,104.60 \pm 7.02$, and 1,317.26 $\pm 197.69 \mathrm{aJ}$ for 0,1 , and 60 seconds, respectively. At 60 seconds surface delays, minor-rupture events were modeled with the worm-like chain model yielding an average contour length of $668 \pm 12 \mathrm{~nm}$. The mean force for $S$. sanguinis minor-detachment events was $1.84 \pm 0.64 \mathrm{nN}$, and Poisson analysis decoupled this value into a short-range force component of $-1.60 \pm 0.34 \mathrm{nN}$ and a long-range force component of $-0.55 \pm 0.47 \mathrm{nN}$. Furthermore, a solution of $2 \mathrm{mg} / \mathrm{mL}$ chlorhexidine was found to increase adhesion between the bacterial probe and substrate. Overall, single-cell force spectroscopy of living $S$. sanguinis cells proved to be a reliable way to characterize early-bacterial adhesion onto machined Ti implant surfaces at the nanoscale.
\end{abstract}

Keywords: atomic force microscopy, biophysics, bacterial adhesion, dental implants, titanium

\section{Introduction}

Amidst rising efforts to combat biofilm-mediated diseases, the prevalence of orthopedic and dental implant infections continues to increase in the population. ${ }^{1}$ Although many biomaterials (such as stainless steel and cobalt-chromium alloys) have been introduced into the clinical setting, titanium (Ti) continues to be considered the "gold standard" material for the elaboration of artificial implants mainly due to its highly biocompatible properties. ${ }^{2,3}$ Ti dental implants have shown excellent survival rates in the past years, ${ }^{4}$ however, the issue of bacterial colonization remains a problem as biofilm formation on the implant surface can lead to loss of osseointegration with subsequent treatment failure. ${ }^{5-7}$ Thus, many chemical disinfection protocols have been developed to try and clean implants after surface infection, in hopes of avoiding surgical intervention and increase the survival rates of affected implants. ${ }^{8}$

Biofilm formation comprises of a series of stages, starting with the initial adhesion of early colonizing species ${ }^{9}$ and continued by the attachment of secondary and increasingly pathogenic bacteria that can lead to disease. ${ }^{10}$ In this context, Streptococcus sanguinis has been consistently reported as an initial colonizer in the process of oral 
biofilm and Ti implant colonization, ${ }^{11}$ with the ability of adhering directly to the surface of biomaterials, giving place to the attachment of secondary bacterial strains. Attachment of $S$. sanguinis to substrates is mostly mediated by adhesins present on the bacterial cell wall surface, ${ }^{12}$ with some studies even describing the existence of bacterial appendages such as pili as contributing factors in adhesion. ${ }^{13}$

In order to understand the initial bacteria-substrate interaction, the process of bacterial adhesion has been characterized according to biophysical models into a "docking phase" and a "locking phase". ${ }^{14}$ During the docking phase, a planktonic bacterium comes into close proximity to a substrate; and the interplay of long-range interactions such as van der Waals and electrostatic forces dictate attraction or repulsion between cell and surface. ${ }^{15}$ This phase can be explained by the Derjaguin, Landau, Vervey, and Overbeek colloidal theory. ${ }^{16}$ In the subsequent locking phase, bacterial receptors attach to the surface in an irreversible manner and secure the bacterium into place. ${ }^{17}$ Bacterial appendages such as pili and capsule are also thought to be involved in this irreversible locking phase stage, where surface de-adhesion can only be obtained by mechanical or chemical removal. ${ }^{13,18}$

Although several methodologies have previously been employed to study bacterial adhesion and colonization to biomedical substrates, the use of atomic force microscopy (AFM) opens new possibilities to characterize the nanoadhesion of bacteria to surfaces with nanonewton and piconewton sensitivity. ${ }^{19}$ In this context, functionalized live-bacterium probes allow the possibility to explore bacterium-surface nanoadhesive interactions by employing techniques such as single-cell force spectroscopy (SCFS) ${ }^{20}$ Currently, one of the preferred approaches for SCFS includes immobilizing bacteria onto colloidal probes to better control the probing contact between bacterial cells and sample surface. ${ }^{21}$ By utilizing bio-based adhesives, it is possible to effectively immobilize bacterial cells to an AFM cantilever and ensure viability for enough time to carry out force measurements. ${ }^{22}$ This approach has been utilized with many different Gram-positive and Gram-negative bacterial species. ${ }^{20,22-24}$ In addition of probing the adhesion force and adhesion work of bacteria against a surface of interest, it is possible to utilize force-extension data to model single-detachment events according to several biopolymer stretching models. ${ }^{25}$ Additionally, values for short-range and long-range forces can be obtained by applying a Poisson analysis to the unbinding data observed at specific contact times. ${ }^{26}$ Utilizing this approach, it is possible to quantify the values for both nonspecific and specific forces driving bacteria toward a surface of interest, and thus gain more insight on the underlying nature of bacteria-substrate interactions.
Currently, there is limited literature regarding the use of AFM to study the adhesion of early implant-colonizing bacteria onto clinically analogous Ti implant surfaces. Therefore in this study, we utilize SCFS to characterize the adhesion of an early implant colonizer, S. sanguinis, onto machined Ti surfaces at the nanoscale.

\section{Materials and methods}

\section{Titanium substrates}

Sterile $15 \mathrm{~mm}$ diameter industrially labeled "smooth" Ti discs provided by Straumann (Basel, Switzerland) were employed throughout this research, which are analogous to smooth implants utilized in the clinical setting. Surface morphology of Ti discs was characterized with a Philips XL30 FEG-SEM (FEI, Eindhoven, the Netherlands) scanning electron microscope ( $5 \mathrm{kV}$ acceleration voltage). AFM characterization (NanoWizard II; JPK Instruments, Berlin, Germany) was performed in contact mode employing NP-S10 probes (Bruker, Santa Barbara, CA, USA) with a spring constant of $0.3 \mathrm{~N} / \mathrm{m}$ at a scanning rate of $1.0 \mathrm{~Hz}$ and scanning size of $10 \times 10 \mu \mathrm{m}$. Surface roughness values $\left(R_{a}\right)$ were obtained both by conventional profilometry (Proscan 1000, Scantron, Somerset, UK) and AFM profilometry (Gwyddion 2.31 software, $n=9,256 \times 256$ pixel scans) for $10 \times 10 \mu \mathrm{m}$ size scans for three independent samples. Surface wettability was calculated by employing an optical contact angle meter with a deionized water droplet (KSV Instruments, CAM 200, Monroe, CT, USA).

\section{Bacterial cultures}

S. sanguinis (ATCC-10556) cells were obtained by growth in brain heart infusion (BHI) broth (Oxoid Ltd, Basingstoke, UK) for 16 hours at $37^{\circ} \mathrm{C}$ and aeration. Previous to AFM experiments, a 20 -fold dilution of bacterial cells was obtained by centrifugation for 1 minute at 5,000 rpm (Eppendorf 5417R, Eppendorf, Stevenage, UK), washing three times and resuspending in TRIS-buffer pH 7.4 (Sigma-Aldrich, Dorset, UK). Finally, a $50 \mu \mathrm{L}$ aliquot of resulting bacterial dilution was transferred to a sterile glass slide for cell probe preparation.

\section{Cell probe fabrication}

For construction of $S$. sanguinis functionalized colloidal probes, an adaptation of a previously reported approach was employed. ${ }^{27}$ Briefly, $\sim 10 \mu \mathrm{m}$ diameter glass microspheres (Whitehouse Scientific, Chester, UK) were attached to NP-O10 tip-less cantilevers (Bruker) by employing a thin layer of ultraviolet (UV)-curable glue (Loctite, Hemel Hempstead, UK). Optical microscopy and scanning electron microscope (SEM) confirmed adequate attachment of a single microsphere on each cantilever. Thermal calibration yielded 
spring constant values of $\sim 0.3 \mathrm{~N} / \mathrm{m}$ (nominal spring constant values $=0.35 \mathrm{~N} / \mathrm{m}$ ). Subsequently, colloidal probes were coated with a poly-dopamine (poly-DOPA) solution for 1 hour, rinsed and dried under $\mathrm{N}_{2}$. Probes were then placed into contact with isolated bacterial cells for $\sim 3$ minutes until attachment was observed, and subsequently positioned over the Ti substrate for force measurements. All constructed cell probes were utilized immediately for force-spectroscopy experiments. A minimum of three independent probes were utilized for analysis.

\section{SCFS force measurements}

SCFS of $S$. sanguinis was performed with a NanoWizard AFM system (JPK Instruments) mounted on an Olympus IX71 (Olympus, Tokyo, Japan) inverted microscope. A minimum of three independent experiments from different bacterial cultures were carried out. Measurements were performed with reduced surface delays of 0 and 1 seconds and an increased surface delay of 60 seconds, with a loading force of $500 \mathrm{pN}$ and a constant speed rate of $2.0 \mu \mathrm{m} / \mathrm{s}$. To minimize the impact of surface topography, measurements were taken on different areas of the sample. Force-curves for DOPAcoated microspheres were employed as controls. As a model to evaluate the effect of a commonplace implant disinfection solution, a $2 \mathrm{mg} / \mathrm{mL}$ concentration of chlorhexidine (CHX) (Sigma-Aldrich, Dorset, UK) in TRIS buffer was added to the system, immersing the probe for 5 minutes before forcecurves were recorded at 60 seconds surface delays.

\section{Data extraction and statistical analysis}

Maximum adhesion force and adhesion work values were collected from resulting force-curves and processed with the JPK Data Analysis software v4.2.61 (JPK Instruments). Results were expressed as mean \pm standard error, and were further analyzed with the Kruskal-Wallis test for nonparametric variables considering significance at $P<0.05$. Minor unbinding events observed at 60 seconds surface delays were fitted to predict contour lengths according to the previously described worm-like chain (WLC) model. ${ }^{28}$ Further decoupling of bacterial adhesion forces was performed with Poisson analysis according to a previously reported approach, ${ }^{29}$ obtaining values for both short-range $\left(F_{\mathrm{SR}}\right)$ and long-range force $\left(F_{\mathrm{LR}}\right)$ components.

\section{Results and discussion \\ Characterization of titanium substrates}

Previous to any bacterial work, surface topographic and chemical characterization of smooth Ti discs was performed and is summarized in Figure 1. SEM and AFM demonstrate a Ti surface topography consistent with previous reports in literature. ${ }^{30}$ Conventional profilometry yielded $\mathrm{R}_{\mathrm{a}}$ values of $0.61 \pm 0.01 \mu \mathrm{m}$ and AFM nano-profilometry showed values of $0.17 \pm 0.02 \mu \mathrm{m}$. As the AFM is able to analyze smaller scan sizes compared to traditional laser profilometry, $\mathrm{R}_{\mathrm{a}}$ values observed for AFM profilometry are more representative of the surface roughness to which bacterial cells will be exposed during adhesion. It has been previously mentioned that implant surfaces with $\mathrm{R}_{\mathrm{a}}$ values $<1 \mu \mathrm{m}$ can be considered smooth and therefore these surfaces are well within the expected parameters. ${ }^{31}$ Average contact angle measurements were found to be $67.0^{\circ} \pm 5.0^{\circ}$, and as surface wettability reflects surface energy, the employed Ti substrates can be considered to be slightly hydrophilic in nature.

\section{S. sanguinis-Ti adhesive interactions}

Functionalization of colloidal probes with $S$. sanguinis was possible with the use of poly-DOPA as an immobilization agent, similar to what has been previously reported for different strains of bacteria and yeast cells. ${ }^{32}$ It is important to consider, however, that as $S$. sanguinis is usually found in chain conformation, it is very difficult to immobilize a unique bacterium onto the microsphere. Nevertheless, this did not seem to affect SCFS measurements as all cell probes presented similar unbinding behavior that allowed for successful comparison and statistical analysis. As the colloidal geometry of the microsphere only allows a reduced area of contact to occur with the Ti surface, the probed adhesive interactions are limited only to a single or reduced number of bacterial cells and therefore similar behavior was observed for all probes. The selection of TRIS buffer maximized the immobilization of bacteria to the probe throughout measurements compared to higher ionic charged buffers like phosphate-buffer saline (PBS). S. sanguinis probes remained viable for approximately 1 hour during measurements, as observed by live/ dead fluorescence staining (data not shown). Experiments for each probe were carried out well under this time limit, and for this reason a reduced number of increased surface delay force-curves (60 seconds) were obtained compared to shorter contact times ( 0 and 1 seconds).

As observed in Figure 2, increasing contact time between the $S$. sanguinis probe and Ti surface generated important changes in the architecture of resulting forcedistance curves. Force-curves obtained at 60 seconds showed increased parameters for maximum adhesion, number of minor-unbinding events, and rupture lengths compared to shorter contact times. Adhesion forces for the $S$. sanguinis probe were found to be $0.32 \pm 0.00,1.07 \pm 0.06$, and $4.85 \pm 0.56 \mathrm{nN}$ for 0,1 , and 60 seconds contact times, respectively. However, only 60 seconds contact 

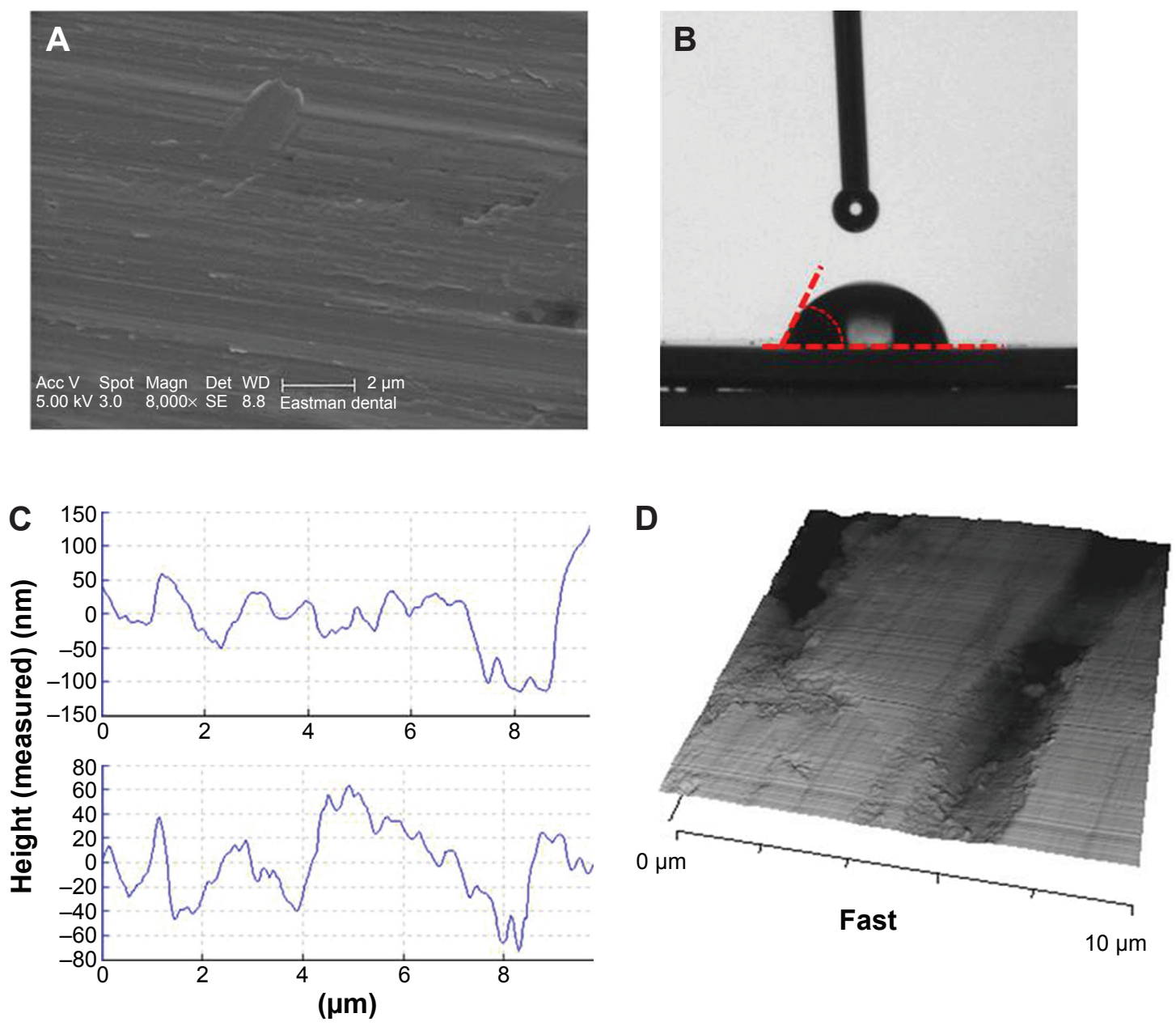

Figure I Ti substrate characterization.

Notes: (A) Representative SEM image of the employed Straumann machined Ti discs. (B) Consistent with previous reports, contact angle measurements were found to be $67.0^{\circ} \pm 5.0^{\circ}$, demonstrating a slightly hydrophilic nature. (C) AFM surface profiles for two independent machined Ti discs, obtained from $10 \times 10 \mu \mathrm{m}$ scans. (D) AFM $3 \mathrm{D}$ reconstruction image showing the topography of machined Ti surfaces with high-resolution $(\mathrm{Z}=700 \mathrm{~nm})$.

Abbreviations: AFM, atomic force microscopy; SEM, scanning electron microscopy; Ti, titanium; 3D, three-dimensional.

times demonstrated a significant difference in maximum adhesion forces when compared to the poly-DOPA control probe $(P<0.05)$. Adhesion work, represented by the integrated area under the retraction curve, was found to be $19.28 \pm 2.38,104.60 \pm 7.02$, and $1,317.26 \pm 197.69$ aJ for 0,1 , and 60 seconds, respectively.

For both studied parameters, higher contact times resulted in increased values compared to decreased surface delays. As cells are compliant in nature, it is believed that longer contact times allow the bacterium to effectively adapt to the geometry and topography of the substrate, generating an increased contact area that allows a higher number of specific interactions to occur between bacteria and Ti surface. It is important to note that the maximum adhesion force value is determined by the magnitude of the major-unbinding peak, which corresponds to the difference between the baseline and the biggest dip in force during probe retraction.
Thus, this value is mainly indicative of the nonspecific force interactions occurring between the bacterial probe and $\mathrm{Ti}$ substrate. Adhesion work, however, also takes into account the minor-unbinding events observed throughout the entire detachment process, and therefore this value is believed to reflect in a more effective manner the overall adhesive interaction between the bacterium probe and surface. Similar results have been previously observed for other streptococcal strains. ${ }^{26,33}$ It is important to note that Ti surfaces employed in this research are clinically analogous substrates and therefore, differences in force measurements caused by surface topography were minimized by obtaining force-curves in several representative areas of the samples. Additionally, these results further demonstrate that bacteria, such as S. sanguinis, can attach directly onto Ti surfaces without the existence of a previously formed biological pellicle. This observation is in line with a recent study by Lorenzetti et al, ${ }^{34}$ which also 


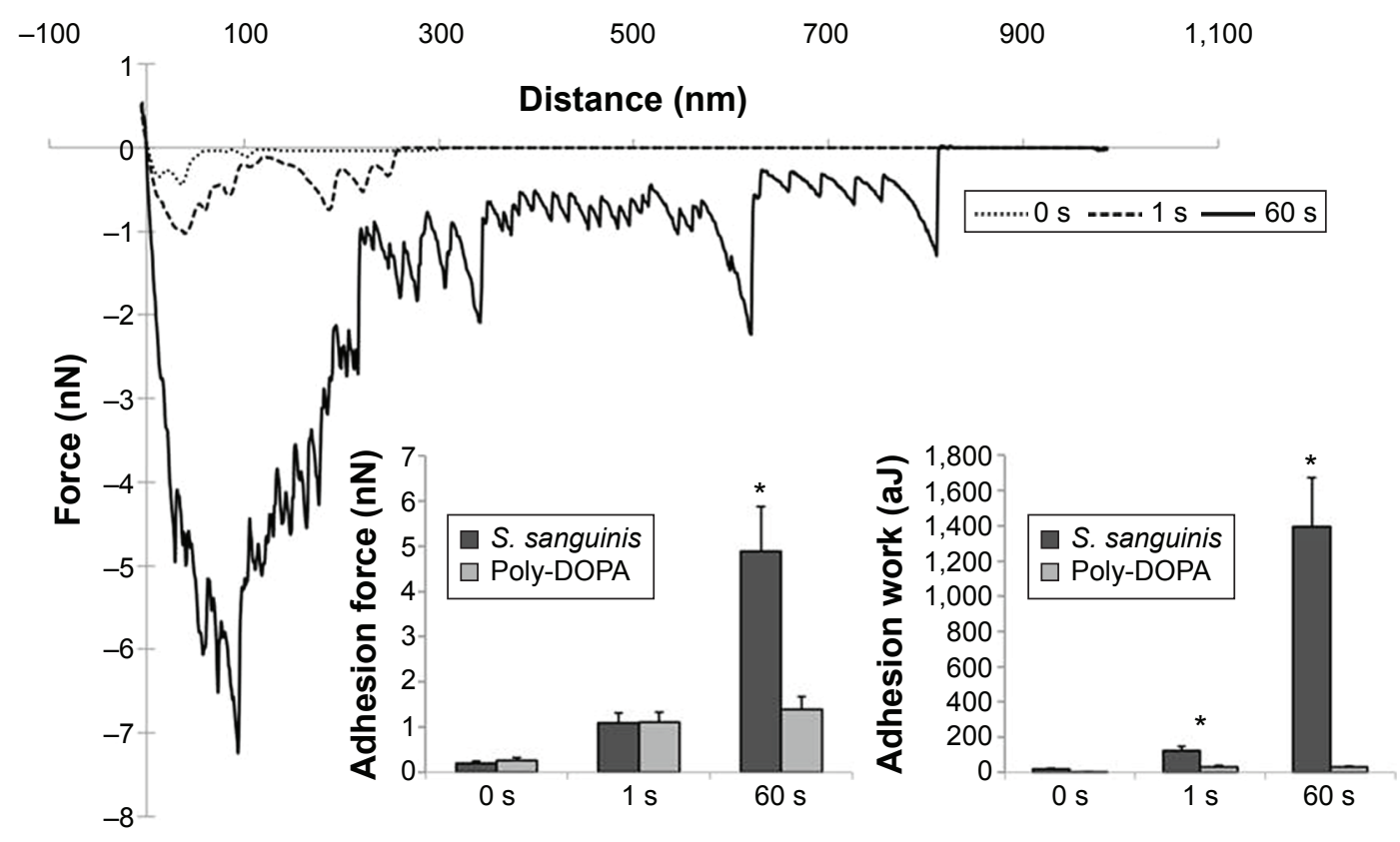

Figure 2 Streptococcus sanguinis-Ti adhesive interactions probed by atomic force microscopy.

Notes: Representative force-curves for the unbinding of $\mathrm{S}$. sanguinis bacterial probes after 0 , I, and 60 seconds surface contact times. Insets show the comparison between bacterial probes and the poly-DOPA coated probes (controls) at each time point for both studied parameters (average of three independent probes) $(* P<0.05$, Kruskal-Wallis).

Abbreviation: $\mathrm{Ti}$, titanium.

observed direct adhesion of Escherichia coli onto nontreated and treated Ti surfaces.

\section{WLC modeling predicts length of bacterial surface molecules}

As it is hypothesized that $S$. sanguinis attaches to hard surfaces by means of cell wall surface adhesins, we modeled the minor-unbinding events found at increased dwelling times with the WLC model given by

$$
\mathrm{F}(\mathrm{x})=\frac{\mathrm{k}_{\mathrm{b}} T}{1_{\mathrm{p}}}\left[\frac{1}{4}\left(1-\frac{x}{L}\right)^{-2}+\frac{x}{L}-\frac{1}{4}\right]
$$

where $\mathrm{F}$ is force $(\mathrm{N}), \mathrm{k}_{\mathrm{b}}$ the Boltzmann constant $(\mathrm{J} /$ Kelvin), $T$ is temperature (Kelvin), $\mathrm{x}$ is the molecular extension (m), $1_{\mathrm{p}}$ is persistence length, and $L$ corresponds to the total contour length of the molecule. In this case, $1_{p}$ was considered as the length of a single amino acid at $\sim 0.36 \mathrm{~nm} .{ }^{23}$ Interestingly, the average contour length predicted for $S$. sanguinis corresponds to $668 \pm 12 \mathrm{~nm}$ ( $\mathrm{n}=661$ unbinding events across three independent probes) (Figure 3A). This value is higher than the contour length reported for Staphylococcus aureus $(314.06 \pm 9.27 \mathrm{~nm})$ using a similar protocol. ${ }^{27}$

Not many reports are available in the literature regarding SCFS experiments with $S$. sanguinis. There are, however, some studies regarding nanoadhesion of other streptococcal strains that may allow for some discussion. Sullan et $\mathrm{al}^{35}$ observed that the unbinding of S. mutans from surfaces coated in salivary agglutinin, fibronectin, and collagen had rupture lengths up to $\sim 6,000, \sim 2,000$, and $\sim 5,000 \mathrm{~nm}$, respectively. For our experiments, however, we observed lower detachment lengths between the $S$. sanguinis probes and smooth Ti. As the Ti substrates employed are uncoated and therefore noncompliant, we believe that the values reported for the unbinding of S. sanguinis are mainly the result of the unfolding of cell wall proteins, accompanied in some extent by a minimal extension of the bacterial membrane. In another study, Francius et al ${ }^{36}$ found the unbinding length between $S$. thermophilus and an abiotic surface to be up to $800 \mathrm{~nm}$, which is comparable to the ones reported in the present study.

\section{Poisson analysis of unbinding events for force decoupling}

To decouple the adhesion between $S$. sanguinis and $\mathrm{Ti}$, a previously reported statistical method known as Poisson analysis was employed ${ }^{29}$ (Figure $3 \mathrm{~B}$ and C). By plotting a linear regression between mean adhesion force $(\mathrm{nN})$ and variance $\left(\mathrm{nN}^{2}\right)$ of the minor unbinding peaks observed between four independent bacterial probes and substrate, it was possible to determine values for $F_{\mathrm{SR}}$ and $F_{\mathrm{LR}}$. It was found 


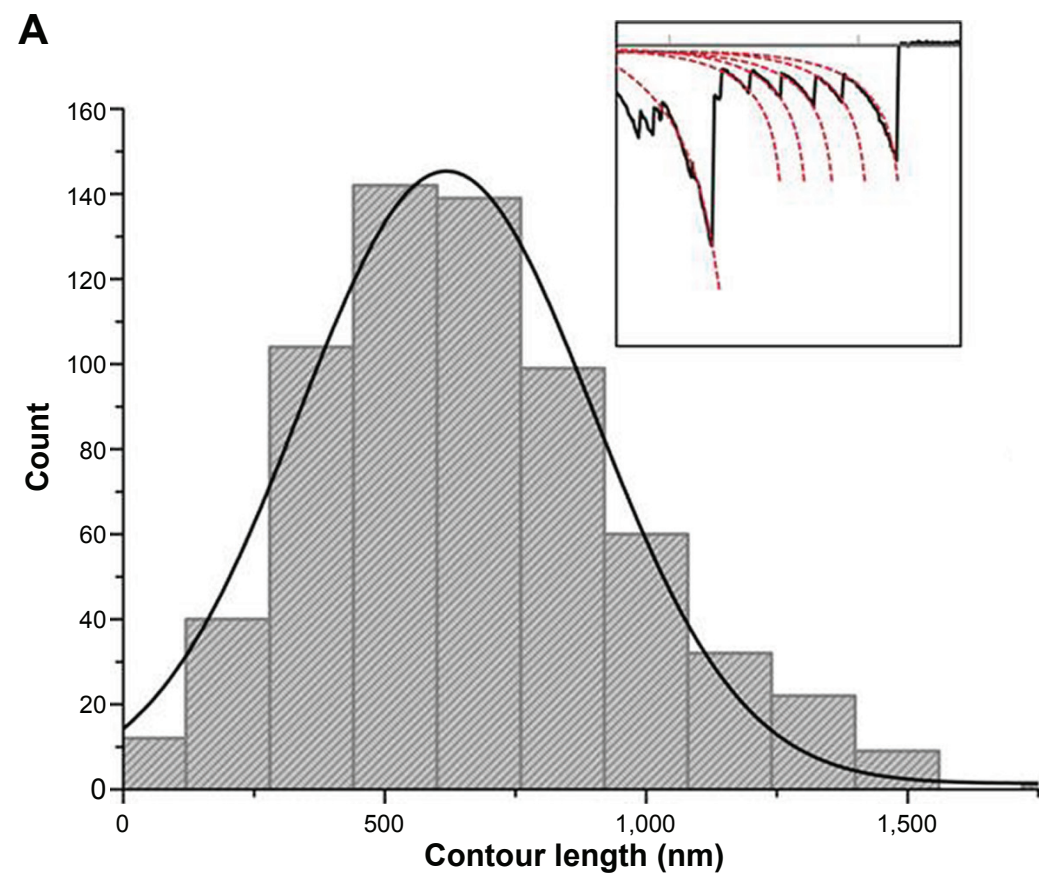

Figure 3 Worm-like chain modeling and Poisson analysis of Streptococcus sanguinis-Ti unbinding events.

Notes: (A) Histogram for the predicted contour length obtained for minor-detachment events across three independent $S$. sanguinis probes ( $\mathrm{n}=66 \mathrm{I}$ events). Inset represents the fitting process carried out on the analysis software. (B) Force histogram for minor-detachment events observed at increased contact times. (C) By plotting average unbinding force against variance for each cell probe, it is possible to predict values for $F_{S R}$ and $F_{L R}$. The analysis for four independent $S$. sanguinis probes is shown ( $R^{2}=0.92$ ). Abbreviations: $F_{\mathrm{LR}}$, long-range force; $F_{\mathrm{SR}}$, short-range force; Ti, titanium.

that the mean value for $S$. sanguinis minor-detachment events was $-1.84 \pm 0.64 \mathrm{nN}$, with an $F_{\mathrm{SR}}$ component of $-1.60 \pm 0.34 \mathrm{nN}$ and an $F_{\mathrm{LR}}$ component of $-0.55 \pm 0.47 \mathrm{nN}$. The negative value observed for $F_{\mathrm{LR}}$ reflects an overall attractive nature of the long-range forces affecting $S$. sanguinis attachment to Ti. Interestingly, $F_{\mathrm{SR}}$ values were higher than the ones observed for $S$. aureus when using the same substrate. ${ }^{27}$ Considering that bacterial attachment to hydrophilic surfaces has been suggested to be predominantly mediated by hydrogen bonding, with an individual bond force of approximately $-0.13 \mathrm{nN},{ }^{37}$ it is possible to hypothesize that a minimum of 12 hydrogen bonds are formed between the $S$. sanguinis cell probe and the surface during AFM probing. This increased bond formation capacity in $S$. sanguinis could help to explain the increased early-colonizing behavior of this strain toward hard surfaces in the oral cavity.

\section{Disrupting minor-unbinding events between S. sanguinis and Ti with $2 \mathrm{mg} / \mathrm{mL}$ $\mathrm{CHX}$}

CHX is one of the most widely used agents for the nonsurgical treatment of infected dental implant surfaces, ${ }^{6}$ and it has the property of remaining active for several hours by adsorbing
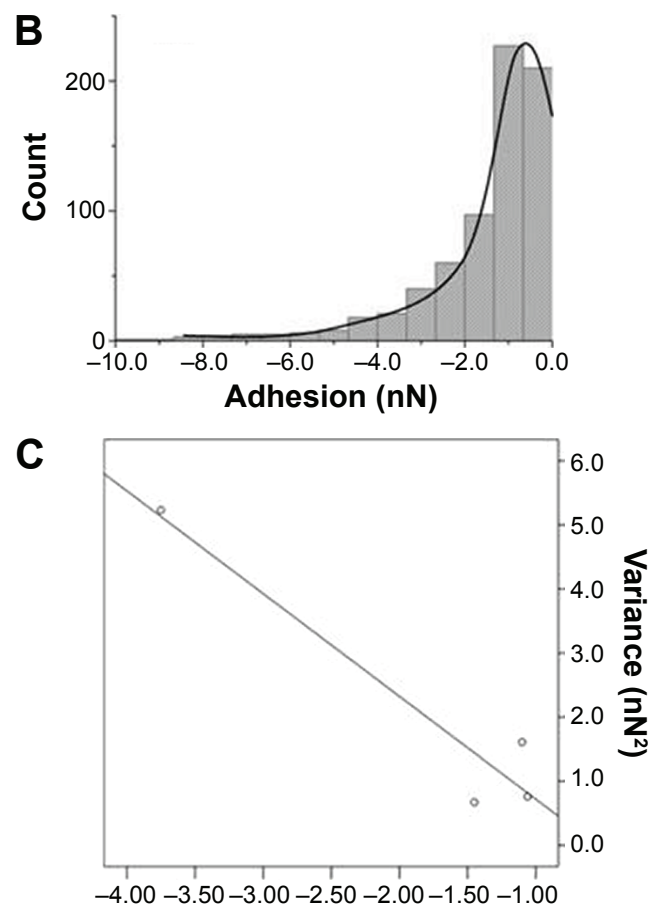

Adhesion $(\mathrm{nN})$ onto surfaces. ${ }^{38}$ However, little is known about the effect this substance has on the early adhesive interaction of oral streptococci bacteria with surfaces. To evaluate the effect of CHX on the adhesion of $S$. sanguinis to Ti surfaces, the initial buffer was replaced by a solution of $2 \mathrm{mg} / \mathrm{mL}$ CHX in TRIS. Significant changes in attachment behavior were observed for both adhesion force and work, as values increased to $47.93 \pm 5.26 \mathrm{nN}$ and 10,473.10 $\pm 1,472.59$ aJ, respectively, after exposure to the CHX solution (Figure 4). The increase in adhesion observed after the application of CHX could be explained by two possible mechanisms. First, CHX is a positively charged molecule with the ability to bind to substrates and negatively charged bacterial surfaces, ${ }^{6}$ and therefore its presence may increase the binding affinity between the probe and Ti surface. Second, CHX exposure has been shown to alter the mechanical properties of the bacterial cell and cause membrane damage, ${ }^{38,39}$ which could also lead to increased adhesion due to increased compliance of the bacterium against the surface during probing. A similar increase in adhesion force and work was observed for $S$. aureus bacterial probes when probed against smooth Ti surfaces in the presence of CHX, however, we found this effect to be more pronounced in the case of S. sanguinis. Nevertheless, further 

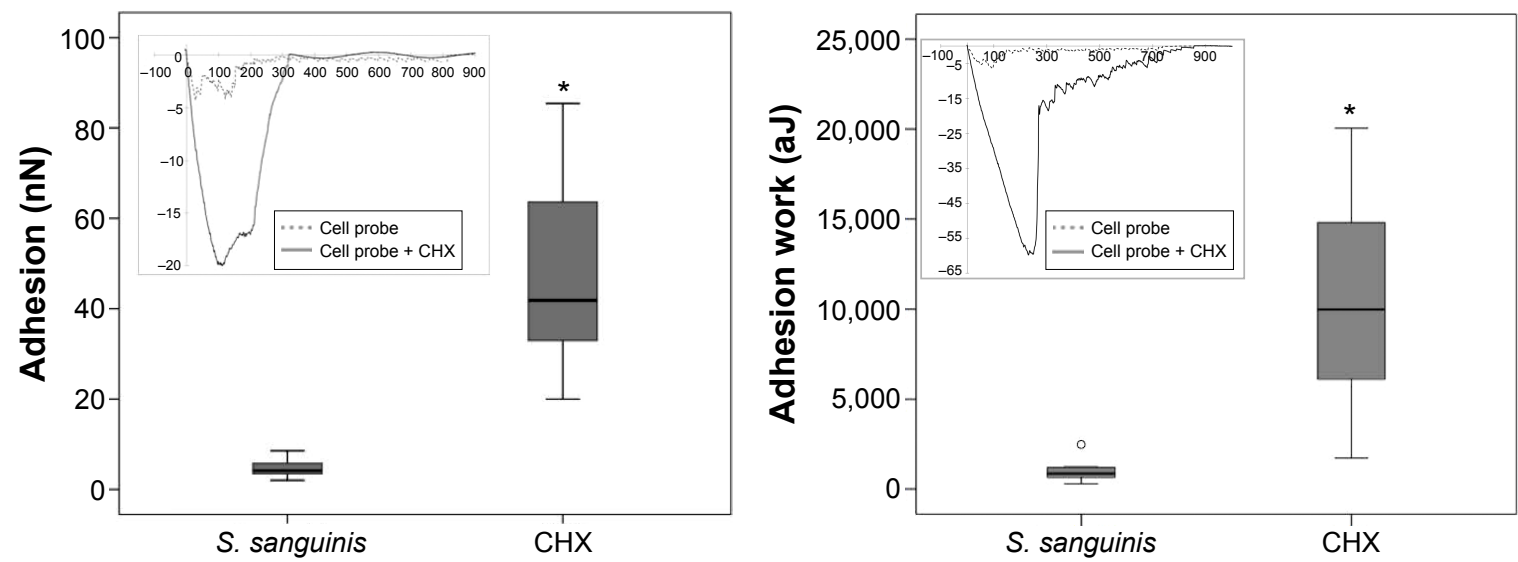

Figure 4 Effect of $2 \mathrm{mg} / \mathrm{mL} \mathrm{CHX}$ on Streptococcus sanguinis-Ti interaction.

Notes: Adhesion force and adhesion work values following the addition of $2 \mathrm{mg} / \mathrm{mL} \mathrm{CHX}$ in TRIS buffer. Increased values for both parameters was observed $(* P<0.05$, Kruskal-Wallis). Insets are representative force-curves demonstrating the changes in unbinding behavior after $\mathrm{CHX}$ exposure. Box plot represents medians and bars represent minimum and maximum values.

Abbreviations: $\mathrm{CHX}$, chlorhexidine; $\mathrm{Ti}$, titanium.

research is necessary to clarify the specific mechanism of CHX-mediated increase in $S$. sanguinis nanoadhesion to Ti surfaces, and to determine the clinical significance this effect could potentially have on biofilm formation postimplant disinfection with CHX. Furthermore, as this AFM approach is not limited only to $S$. sanguinis and Ti surfaces, it can potentially be employed as a tool to evaluate the impact of antiadhesive surfaces, coatings, or solutions on the attachment of a diverse number of bacterial strains to implant surfaces, in hope of preventing surface colonization and infection.

\section{Conclusion}

SCFS of living S. sanguinis cells proved to be a reliable way to characterize the nature of their adhesion onto clinically analogous smooth Ti surfaces at different contact times. Within the limitations of this study, it was possible to characterize and decouple adhesion forces between an S. sanguinis bacterial probe and a clinically analogous Ti implant surface. Values for both adhesion force and adhesion work were found to increase at higher surface delays and were significantly higher than the poly-DOPA controls, and thus believed to directly reflect the interaction between immobilized S. sanguinis cells and the Ti substrate. Predicted contour lengths for single-unbinding events are consistent with previous reports in literature for similar streptococcal strains, and force-decoupling at 60 seconds contact times demonstrated that $S$. sanguinis attaches to $\mathrm{Ti}$ surfaces predominantly though specific short-range adhesive forces. Therefore, as Ti substrates employed in this study were found to be hydrophilic, we suggest hydrogen bonding as the principal driving force in the initial phase of streptococcal adhesion to Ti surfaces. Finally, the addition of a CHX solution to the system generated increased values for both adhesion force and work parameters. Hopefully, these results will give new insight on the use of SCFS for the study of bacterial adhesion onto clinically representative biomaterial surfaces.

\section{Acknowledgment}

The authors would kindly like to thank the BecasChile $\mathrm{PhD}$ Scholarship Programme for funding this research.

\section{Author contributions}

SA contributed with data acquisition and analysis, and drafted the manuscript; ND contributed to the study conception, design, data analysis and interpretation, and critically revised the manuscript; DS contributed to conception, design, and critically revised the manuscript; and LB contributed to conception, design, data analysis and interpretation, and critically revised the manuscript.

\section{Disclosure}

The authors report no conflicts of interest in this work.

\section{References}

1. Logan N, Brett P. The control of mesenchymal stromal cell osteogenic differentiation through modified surfaces. Stem Cells Int. 2013; 2013:361637.

2. Geetha M, Singh AK, Asokamani R, Gogia AK. Ti based biomaterials, the ultimate choice for orthopaedic implants - A review. Prog Mater Sci. 2009;54(3):397-425.

3. Webb HK, Boshkovikj V, Fluke CJ, et al. Bacterial attachment on sub-nanometrically smooth titanium substrata. Biofouling. 2013;29(2): 163-170.

4. Albrektsson T, Donos N, Working Group 1. Implant survival and complications. The Third EAO consensus conference 2012. Clin Oral Implants Res. 2012;23 Suppl 6:63-65. 
5. Donos N, Laurell L, Mardas N. Hierarchical decisions on teeth vs. implants in the periodontitis-susceptible patient: the modern dilemma. Periodontol. 2000. 2012;59(1):89-110.

6. Valderrama P, Blansett JA, Gonzalez MG, Cantu MG, Wilson TG. Detoxification of implant surfaces affected by peri-implant disease: an overview of non-surgical methods. Open Dent J. 2014;8:77-84.

7. Wu X, Al-Abedalla K, Rastikerdar E, et al. Selective serotonin reuptake inhibitors and the risk of osseointegrated implant failure: a cohort study. J Dent Res. 2014;93(11):1054-1061.

8. Renvert S, Roos-Jansaker AM, Claffey N. Non-surgical treatment of peri-implant mucositis and peri-implantitis: a literature review. J Clin Periodontol. 2008;35(8 Suppl):305-315.

9. Hojo K, Nagaoka S, Ohshima T, Maeda N. Bacterial interactions in dental biofilm development. J Dent Res. 2009;88(11):982-990.

10. Renvert S, Lindahl C, Renvert H, Persson GR. Clinical and microbiological analysis of subjects treated with Branemark or AstraTech implants: a 7-year follow-up study. Clin Oral Implants Res. 2008;19(4): 342-347.

11. Rodriguez-Hernandez AG, Juarez A, Engel E, Gil FJ. Streptococcus sanguinis adhesion on titanium rough surfaces: effect of shot-blasting particles. J Mater Sci Mater Med. 2011;22(8):1913-1922.

12. Yamaguchi M, Terao Y, Ogawa T, Takahashi T, Hamada S, Kawabata S. Role of Streptococcus sanguinis sortase A in bacterial colonization. Microbes Infect. 2006;8(12-13):2791-2796.

13. Okahashi N, Nakata M, Sakurai A, et al. Pili of oral Streptococcus sanguinis bind to fibronectin and contribute to cell adhesion. Biochem Biophys Res Commun. 2010;391(2):1192-1196.

14. Gordesli FP, Abu-Lail NI. Combined Poisson and soft-particle DLVO analysis of the specific and nonspecific adhesion forces measured between L. monocytogenes grown at various temperatures and silicon nitride. Environ Sci Technol. 2012;46(18):10089-10098.

15. Harimawan A, Zhong S, Lim CT, Ting YP. Adhesion of B. subtilis spores and vegetative cells onto stainless steel - DLVO theories and AFM spectroscopy. J Colloid Interface Sci. 2013;405:233-241.

16. Chen Y, Harapanahalli AK, Busscher HJ, Norde W, van der Mei HC. Nanoscale cell wall deformation impacts long-range bacterial adhesion forces on surfaces. Appl Environ Microbiol. 2014;80(2):637-643.

17. Katsikogianni M, Missirlis YF. Concise review of mechanisms of bacterial adhesion to biomaterials and of techniques used in estimating bacteria-material interactions. European Cell Mater. 2004;8:37-57.

18. Tripathi P, Beaussart A, Alsteens D, et al. Adhesion and nanomechanics of pili from the probiotic Lactobacillus rhamnosus GG. ACS Nano. 2013; 7(4):3685-3697.

19. Vukosavljevic D, Hutter JL, Helmerhorst EJ, et al. Nanoscale adhesion forces between enamel pellicle proteins and hydroxyapatite. J Dent Res. 2014;93(5):514-519.

20. Aguayo S, Donos N, Spratt D, Bozec L. Single-bacterium nanomechanics in biomedicine: unravelling the dynamics of bacterial cells. Nanotechnology. 2015;26(6):062001.

21. Beaussart A, El-Kirat-Chatel S, Sullan RM, et al. Quantifying the forces guiding microbial cell adhesion using single-cell force spectroscopy. Nat Protoc. 2014;9(5):1049-1055.

22. Beaussart A, El-Kirat-Chatel S, Herman P, et al. Single-cell force spectroscopy of probiotic bacteria. Biophys J. 2013;104(9):1886-1892.
23. Herman P, El-Kirat-Chatel S, Beaussart A, Geoghegan JA, Foster TJ, Dufrene YF. The binding force of the staphylococcal adhesin SdrG is remarkably strong. Mol Microbiol. 2014;93(2):356-368.

24. Beaussart A, Herman P, El-Kirat-Chatel S, et al. Single-cell force spectroscopy of the medically important Staphylococcus epidermidisCandida albicans interaction. Nanoscale. 2013;5(22):10894-10900.

25. Chan Y, Haverkamp RG, Hill JM. Force-extension formula for the worm-like chain model from a variational principle. J Theor Biol. 2010; 262(3):498-504.

26. Mei L, Ren Y, Busscher HJ, Chen Y, van der Mei HC. Poisson analysis of streptococcal bond-strengthening on saliva-coated enamel. J Dent Res. 2009;88(9):841-845.

27. Aguayo S, Donos N, Spratt D, Bozec L. Nanoadhesion of Staphylococcus aureus onto titanium implant surfaces. J Dent Res. 2015;94(8): 1078-1084.

28. Storm C, Nelson PC. Theory of high-force DNA stretching and overstretching. Phys Rev E Stat Nonlin Soft Matter Phys. 2003;67(5 Pt 1): 051906.

29. Chen Y, Busscher HJ, van der Mei HC, Norde W. Statistical analysis of long- and short-range forces involved in bacterial adhesion to substratum surfaces as measured using atomic force microscopy. Appl Environ Microbiol. 2011;77(15):5065-5070.

30. Logan N, Sherif A, Cross AJ, et al. $\mathrm{TiO}_{2}$-coated CoCrMo: Improving the osteogenic differentiation and adhesion of mesenchymal stem cells in vitro. J Biomed Mater Res A. 2015;103(3):1208-1217.

31. Sykaras N, Iacopino AM, Marker VA, Triplett RG, Woody RD. Implant materials, designs, and surface topographies: their effect on osseointegration. A literature review. Int J Oral Maxillofac Implants. 2000;15(5):675-690.

32. Dufrene YF. Sticky microbes: forces in microbial cell adhesion. Trends Microbiol. 2015;23(6):376-382.

33. Mei L, Busscher HJ, van der Mei HC, Ren Y. Influence of surface roughness on streptococcal adhesion forces to composite resins. Dent Mater. 2011;27(8):770-778.

34. Lorenzetti M, Dogsa I, Stosicki T, et al. The influence of surface modification on bacterial adhesion to titanium-based substrates. ACS Appl Mater Interfaces. 2015;7(3):1644-1651.

35. Sullan RM, Li JK, Crowley PJ, Brady LJ, Dufrene YF. Binding forces of Streptococcus mutans P1 adhesin. ACS Nano. 2015;9(2):1448-1460.

36. Francius G, Henry R, Duval JF, et al. Thermo-regulated adhesion of the Streptococcus thermophilus $\Delta$ gg0182 strain. Langmuir. 2013; 29(15):4847-4856.

37. Abu-Lail NI, Camesano TA. Specific and nonspecific interaction forces between Escherichia coli and silicon nitride, determined by Poisson statistical analysis. [Erratum appears in Langmuir. 2008;24(8):4420.] Langmuir. 2006;22(17):7296-7301

38. Edmiston CE Jr, Bruden B, Rucinski MC, Henen C, Graham MB, Lewis BL. Reducing the risk of surgical site infections: does chlorhexidine gluconate provide a risk reduction benefit? Am J Infect Control. 2013;41(5 Suppl):S49-S55.

39. McDonnell G, Russell AD. Antiseptics and disinfectants: activity, action, and resistance. Clin Microbiol Rev. 1999;12(1):147-179.
International Journal of Nanomedicine

\section{Publish your work in this journal}

The International Journal of Nanomedicine is an international, peerreviewed journal focusing on the application of nanotechnology in diagnostics, therapeutics, and drug delivery systems throughout the biomedical field. This journal is indexed on PubMed Central, MedLine, CAS, SciSearch ${ }^{\circledR}$, Current Contents ${ }^{\circledR} /$ Clinical Medicine,

\section{Dovepress}

Journal Citation Reports/Science Edition, EMBase, Scopus and the Elsevier Bibliographic databases. The manuscript management system is completely online and includes a very quick and fair peer-review system, which is all easy to use. Visit http://www.dovepress.com/ testimonials.php to read real quotes from published authors. 